\title{
Comparative Study of Inhaler Device Handling Technique and Risk Factors for Critical Inhaler Errors in Korean COPD Patients
}

\author{
Jong Geol Jang (D) \\ Jin Hong Chung $\mathbb{D}$ \\ Kyeong-Cheol Shin (iD \\ Hyun Jung Jin \\ Kwan Ho Lee \\ June Hong Ahn (D)
}

Department of Internal Medicine, Division of Pulmonology and Allergy, College of Medicine, Yeungnam University and Regional Center for Respiratory Diseases, Yeungnam University Medical Center, Daegu, Republic of Korea
Correspondence: Kwan Ho Lee; June Hong Ahn

Department of Internal Medicine, Division of Pulmonology and Allergy, College of Medicine, Yeungnam University and Regional Center for Respiratory Diseases, Yeungnam University Medical Center, 170 Hyeonchung-ro, Namgu,

Daegu, 42415, Republic of Korea Tel +82-53-640-660I; +82-53-640-6577 Fax +82-53-620-3849

Email ghlee@med.yu.ac.kr;

fireajh@gmail.com
Objective: Critical inhaler handling errors are associated with an increased risk of adverse outcomes in patients with chronic obstructive pulmonary disease (COPD). However, realworld data on inhaler device handling techniques and the risk factors for critical inhaler errors in the Asian population have been examined in only a few studies. We evaluated the rates and risk factors for critical inhaler errors in the COPD population in Korea.

Methods: COPD patients were prospectively enrolled from January 2018 to November 2019. An advanced practice nurse evaluated their inhaler technique. The 308 inhalers used by the 261 participants in this study included dry powder inhalers (DPIs; Turbuhaler, Breezhaler, Ellipta, Diskus, Genuair), a soft mist inhaler (SMI; Respimat), and pressurized metered dose inhalers (pMDIs).

Results: The percentage critical errors for Turbuhaler, Breezhaler, Ellipta, Diskus, Genuair, Respimat, and pMDI usage were $60.0 \%, 41.0 \%, 27.8 \%, 12.5 \%, 44.4 \%, 45.5 \%$, and $55.0 \%$, respectively. In the multivariate analyses, female sex, short COPD duration, dissatisfaction with the inhaler (assessed by FSI-10), and moderate acute exacerbations (AEs) in the prior year were independent risk factors for any critical error in the DPI group. In the SMI group, a low education level and frequent AEs in the prior year were independent risk factors for any critical error, whereas a high COPD assessment test (CAT) score was the only risk factor in the pMDI group.

Conclusion: Critical inhaler errors are common among patients with COPD, regardless of their preferred inhaler device. The rates and risk factors for critical inhaler errors differed among patients using different devices. Optimal device selection considering the risk factors of inhaler misusage will improve disease control in COPD patients.

Keywords: COPD, inhalation therapy, error, risk factor

\section{Introduction}

The prevalence of chronic obstructive pulmonary disease (COPD) in South Korea ranged from $13.1 \%$ to $14.6 \%$ from 2010 to 2015 , and COPD remains one of the 10 major causes of death in the country. ${ }^{1,2}$ Inhalation therapy with bronchodilators is a cornerstone of the pharmacological treatment of COPD. However, critical inhaler handling errors are associated with an increased risk of adverse outcomes in COPD patients. ${ }^{3,4}$ The Global Initiative for Chronic Obstructive Lung Disease (GOLD) 2019 management cycle recommends an assessment of inhaler technique and adherence and of non-pharmacological approaches such as pulmonary rehabilitation and patient education. ${ }^{5}$ However, few studies have compared inhaler device 
handling technique and the risk factors for critical inhaler errors in the Asian COPD population. ${ }^{6,7}$ Thus, in this study we evaluated the rates and risk factors for any critical inhaler error in the COPD population in South Korea.

\section{Methods}

\section{Study Design and Subjects}

This prospective cross-sectional study was conducted in the pulmonology outpatient department of the Regional Center for Respiratory Disease, Yeungnam University Hospital (a tertiary university hospital in Daegu, South Korea) from January 2018 to November 2019. Patients $\geq 40$ years of age who had been diagnosed with COPD were initially enrolled. From this group, all patients who had used an inhaler of any kind for $>1$ month were included. This study was a secondary analysis of data used in a previous publication ${ }^{8}$ and based on the same number of patients. The 261 patients used 308 inhalers, including dry powder inhalers (DPIs; Turbuhaler, Breezhaler, Ellipta, Diskus, Genuair), a soft mist inhaler (SMI; Respimat), and pressurized metered dose inhalers (pMDIs). Patients using other inhalers, those with advanced cancer, and pregnant females were excluded. The study was conducted in accordance with all relevant tenets of the Declaration of Helsinki. The protocol was reviewed and approved by the Institutional Review Board of our hospital (no. YUH IRB 2017-09-012-001). Written informed consent was obtained from all patients.

\section{Data Collection and Definitions}

An advanced practice nurse specializing in inhaler education conducted all of the interviews regarding inhaler handling technique and adherence. Critical errors were defined as errors seriously compromising drug delivery to the lung. The types of critical errors considered in this study were stratified by device type and are listed in Supplementary Table 1. Critical errors included dose preparation and dose delivery errors. Adherence was selfreported and graded as good, partial, or poor, according to whether the entire daily dose was taken, the daily dose (frequency or amount) taken was more or less than that required, and the medication was taken only as needed or not at all, respectively. ${ }^{9}$ As described in the previous study, ${ }^{8}$ all patients completed a general questionnaire (age, sex, body mass index, total number of inhalations per day, smoking status, duration of COPD, previous education for handling an inhaler, previous education for COPD, level of education), a modified Medical Research Council (mMRC) survey, a COPD assessment test (CAT), the Mini-Mental State Examination (MMSE), the EuroQol-5D (EQ-5D) questionnaire, a patient health questionnaire (PHQ-9), and the Feeling of Satisfaction with the Inhaler (FSI-10) questionnaire.

\section{Statistical Analysis}

Continuous variables are expressed as the mean \pm standard deviation and were compared using Student's $t$-test or the Mann-Whitney $U$-test. Categorical variables were compared using the chi-squared test or Fisher's exact test. Factors associated with any critical error variables with a $P$-value $<0.1$ in the univariate analyses were further analyzed in multivariate analyses that determined odds ratios (ORs) and 95\% confidence intervals (CIs). Age and sex were also included in the multivariate logistic regression analyses. In all analyses, a two-tailed $P$-value $<0.05$ was considered to indicate statistical significance. All statistical analyses were performed using SPSS software (ver. 24.0; SPSS Inc., Chicago, IL, USA). A prospective power calculation indicated that an overall sample size of 220 was required to evaluate the efficacy of education ( $95 \%$ power, $\alpha=0.05$, effect size $=0.3$ ). To account for any dropouts, 260 patients were enrolled. ${ }^{10}$

\section{Results}

\section{Baseline Characteristics}

The baseline characteristics of the COPD patients according to inhaler technique are summarized in Table 1 . The mean age of the patients was $69.8 \pm 7.7$ years, and males predominated in both the correct-usage group (98.6\%) and the any-critical-error group $((87.7 \%), P<0.001)$. The mean body mass index was $23.5 \pm 3.5 \mathrm{~kg} / \mathrm{m}^{2}$. The percentage of patients with good adherence was higher in the correct-usage group $(87.8 \%$ vs $74.6 \%, P=0.008)$ than in the any-critical-error group. Of all patients, $37.9 \%$ had a low level of education. The percentage of patients with a high education level ( $>6$ years) was higher in the correct-usage group than in the any-critical-error group (68.3\% vs $54.9 \%, P=0.026)$. Compared to patients in the correct-usage group, those in the any-critical-error group were significantly more likely to have a low diffusion capacity for carbon monoxide $(70.9 \pm 20.5$ vs $65.5 \pm$ $18.0, P=0.027)$, a high GOLD III, IV stage $(15.8 \%$ vs $28.7 \%, P=0.012)$, a high mMRC score $(1.1 \pm 0.8$ vs $1.5 \pm$ 
Table I Baseline Characteristics of the COPD Patients According to Correct or Erroneous Inhaler Usage

\begin{tabular}{|c|c|c|c|c|}
\hline Variable & Total $(n=26 I)$ & Correct Usage $(n=139)$ & Any Critical Error $(n=\mid 22)$ & $P$-value \\
\hline Age (years) & $69.8 \pm 7.7$ & $69.6 \pm 7.2$ & $69.9 \pm 8.2$ & 0.729 \\
\hline Male, n (\%) & $244(93.5)$ & $137(98.6)$ & $107(87.7)$ & $<0.001$ \\
\hline Body mass index $\left(\mathrm{kg} / \mathrm{m}^{2}\right)$ & $23.5 \pm 3.5$ & $23.9 \pm 3.4$ & $23.1 \pm 3.5$ & 0.050 \\
\hline Puff burden & $2.2 \pm 1.3$ & $1.9 \pm 0.9$ & $2.6 \pm 1.5$ & $<0.001$ \\
\hline Adherence & & & & 0.008 \\
\hline Good & $213(81.6)$ & $122(87.8)$ & 91 (74.6) & \\
\hline Partial & $42(16.1)$ & $15(10.8)$ & $27(22.3)$ & \\
\hline Poor & $6(2.3)$ & $2(1.4)$ & $4(3.3)$ & \\
\hline COPD duration (years) & $3.6 \pm 4.3$ & $3.7 \pm 4.5$ & $3.4 \pm 4.2$ & 0.631 \\
\hline Previous education on COPD & $249(95.4)$ & $133(95.7)$ & $116(95.1)$ & 0.817 \\
\hline Previous education on inhaler use & $249(95.4)$ & $135(97.1)$ & $114(93.4)$ & 0.157 \\
\hline Educational level & & & & 0.026 \\
\hline Low ( $\leq 6$ years) & 99 (37.9) & $44(31.7)$ & $55(45.1)$ & \\
\hline High (> 6 years) & $162(62.1)$ & $95(68.3)$ & $67(54.9)$ & \\
\hline $\mathrm{FEV}_{1} / \mathrm{FVC}(\%)$ & $58.6 \pm 13.7$ & $59.4 \pm 12.7$ & $57.7 \pm 14.8$ & 0.344 \\
\hline Percentage predicted $\mathrm{FEV}_{\text {, }}$ & $63.5 \pm 17.5$ & $64.4 \pm 15.4$ & $62.4 \pm 19.6$ & 0.373 \\
\hline Percentage predicted DLCO $(n=258)$ & $68.4 \pm 19.5$ & $70.9 \pm 20.5$ & $65.5 \pm 18.0$ & 0.027 \\
\hline GOLD stage & & & & 0.012 \\
\hline I, II & $204(78.1)$ & $117(84.2)$ & $87(7 \mid .3)$ & \\
\hline III, IV & $57(21.9)$ & $22(15.8)$ & $35(28.7)$ & \\
\hline mMRC score & $1.3 \pm 0.9$ & $1.1 \pm 0.8$ & $1.5 \pm 0.9$ & 0.001 \\
\hline CAT score & $9.9 \pm 5.6$ & $9.1 \pm 4.7$ & $10.8 \pm 6.3$ & 0.018 \\
\hline MMSE score $(n=258)$ & $29.3 \pm 1.6$ & $29.6 \pm 1.1$ & $29.2 \pm 2.0$ & 0.030 \\
\hline FSI-I0 score & $44.4 \pm 4.7$ & $45.2 \pm 4.3$ & $43.4 \pm 4.9$ & 0.001 \\
\hline PHQ-9 score & $1.1 \pm 2.3$ & $1.3 \pm 2.6$ & $1.0 \pm 1.9$ & 0.298 \\
\hline EQ-5D score & $0.9 \pm 0.1$ & $0.9 \pm 0.1$ & $0.8 \pm 0.1$ & 0.028 \\
\hline Frequent exacerbations in the prior year & $65(24.9)$ & $26(18.7)$ & $39(32.0)$ & 0.013 \\
\hline
\end{tabular}

Note: Data are presented as the mean \pm standard deviation or number (percentage).

Abbreviations: CAT, COPD assessment test; COPD, chronic obstructive pulmonary disease; DLCO, diffusion capacity for carbon monoxide; EQ-5D, EuroQol-5D; FEV forced expiratory volume in I second; FSI-I0, Feeling of Satisfaction with Inhaler questionnaire; FVC, forced vital capacity; GOLD, Global Initiative for Chronic Obstructive Lung Disease; mMRC, modified Medical Research Council; MMSE, Mini-Mental State Examination; PHQ-9, patient health questionnaire.

$0.9, P=0.001)$, a high CAT score $(9.1 \pm 4.7$ vs $10.8 \pm 6.3$, $P=0.018)$, a low MMSE score $(29.6 \pm 1.1$ vs $29.2 \pm 2.0$, $P=0.030)$, a low FSI-10 score $(45.2 \pm 4.3$ vs $43.4 \pm 4.9$, $P=0.001)$, a low EQ-5D score $(0.9 \pm 0.1$ vs $0.8 \pm 0.1, P=$ 0.028 ), and more frequent acute exacerbations (AEs) in the prior year $(18.7 \%$ vs $32.0 \%, P=0.013)$.

\section{Assessment of Inhaler Technique}

The percentages of inhaler errors, including preparation errors, delivery errors, and any critical errors, associated with each of the evaluated inhaler types are shown in Figure 1. The percentages of any critical errors for patients using the Turbuhaler, Breezhaler, Ellipta, Diskus, Genuair, and 


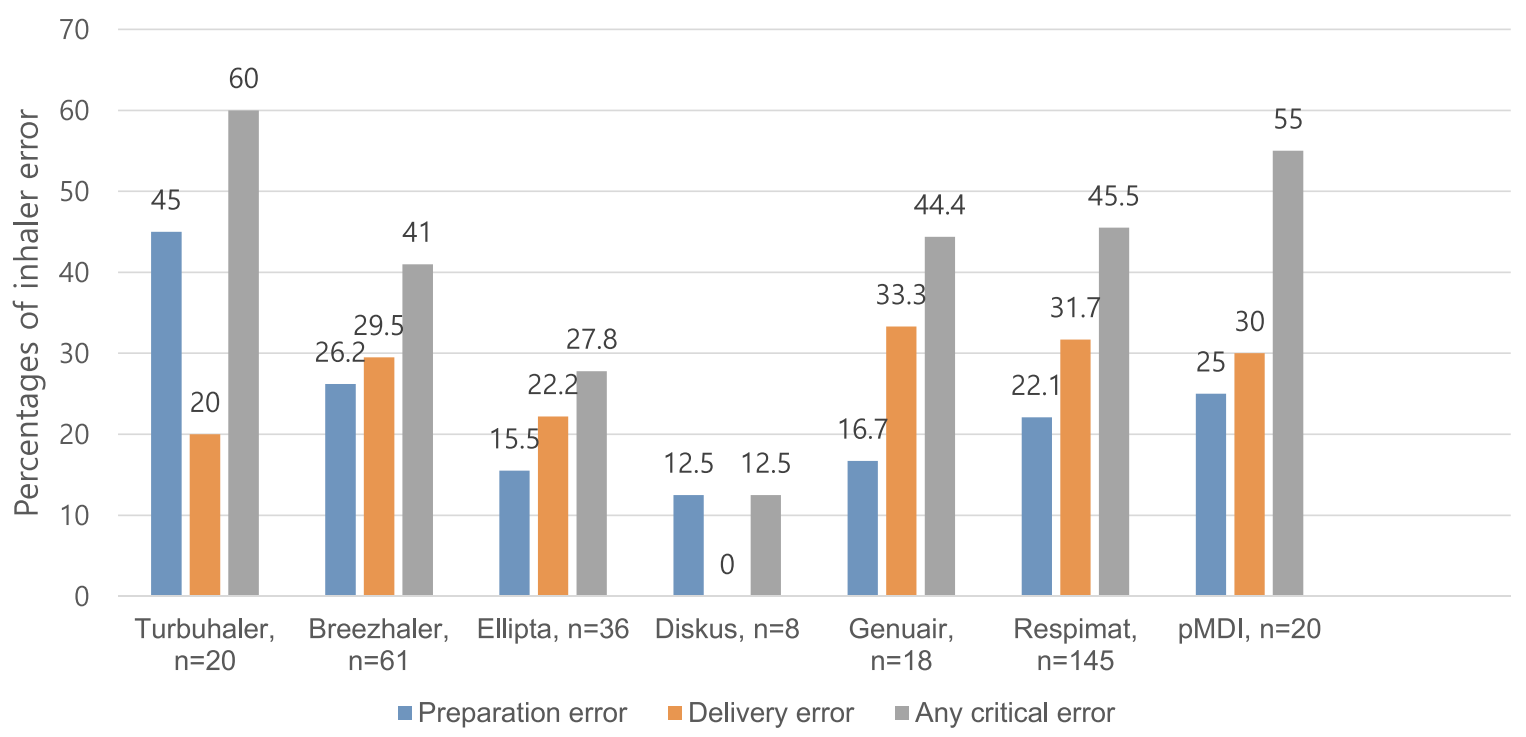

Figure I Percentages of any overall error and any critical error for each inhaler type.

Respimat inhalers and pMDIs were $60.0 \%, 41.0 \%, 27.8 \%$, $12.5 \%, 44.4 \%, 45.5 \%$, and $55.0 \%$, respectively. Preparation errors were most commonly found among patients using Turbuhaler, followed by those using Breezhaler, pMDIs, Respimat, Genuair, Ellipta, and Diskus. Delivery errors were more commonly associated with Genuair, Respimat, pMDI, Breezhaler, Ellipta, Turbuhaler, and Diskus inhalers.

\section{Factors Associated with Any Critical Error for Each Inhaler}

The results of the univariate analyses of factors associated with any critical errors for each inhaler type are shown in Table 2. An analysis of the DPI group showed that female sex, a high mMRC score, low FSI-10 score, and moderate AEs in the prior year were associated with critical inhaler error. For patients using a SMI, a low education level, low EQ-5D score, and frequent AEs in the prior year were associated with critical inhaler error. In the pMDI group, the only independent risk factor for any critical error was a high CAT score. In the multivariate analyses, independent risk factors for any critical error included female sex, short COPD duration, a low FSI-10 score, and moderate AEs in the prior year in the DPI group; a low education level and frequent AEs in the prior year in the SMI group; and a high CAT score in the pMDI group (Table 3 ).

\section{Discussion}

Among the 261 COPD patients, critical errors were observed in $46.7 \%$ (122/261), and among the 308 inhalers used by the patients, critical errors occurred in association with usage of the Turbuhaler, Breezhaler, Ellipta, Diskus, Genuair, and Respimat inhalers and pMDIs at rates of $60.0 \%, 41.0 \%, 27.8 \%, 12.5 \%, 44.4 \%, 45.5 \%$, and 55.0\%, respectively. Independent risk factors for any critical error were female sex, short COPD duration, a low FSI-10 score, and moderate AEs in the prior year in the DPI group; a low education level and frequent AEs in the prior year in the SMI group; and a high CAT score in the pMDI group.

The percentages of any critical error according to inhaler type were higher for Turbuhaler, pMDI, Respimat, and Breezhaler inhalers. These results are in accordance with a recent large real-world study from Europe in which the percentages of any critical error were higher for Respimat, pMDI, Handihaler, and Turbuhaler users. ${ }^{11}$ Dividing the critical error into dose preparation and dose delivery errors revealed differences among devices, with many errors occurring for each device type. In our study, dose preparation errors were most common in the group using Turbuhaler, followed by the groups using the Breezhaler, pMDIs, and Respimat; dose delivery errors were more commonly associated with the use of Genuair, Respimat, pMDI, and Breezhaler inhalers. In the European study, dose preparation errors were common among Respimat and Turbuhaler users, and dose delivery errors among Respimat and pMDI users. ${ }^{11}$ Overall, the results of that study did not significantly differ from ours with respect to the proportion and type of critical errors occurring with each device. 
Table 2 Factors Associated with Any Critical Error for Each Inhaler Type

\begin{tabular}{|c|c|c|c|c|c|c|c|c|c|}
\hline & \multicolumn{3}{|c|}{ DPI $(n=143)$} & \multicolumn{3}{|c|}{ SMI $(n=145)$} & \multicolumn{3}{|c|}{ pMDI $(n=20)$} \\
\hline & $\begin{array}{l}\text { Correct } \\
\text { Usage } \\
(n=87)\end{array}$ & $\begin{array}{c}\text { Any } \\
\text { Critical } \\
\text { Error } \\
(n=56)\end{array}$ & $P$-value & $\begin{array}{l}\text { Correct } \\
\text { Usage } \\
(n=79)\end{array}$ & $\begin{array}{c}\text { Any } \\
\text { Critical } \\
\text { Error } \\
(n=66)\end{array}$ & $P$-value & $\begin{array}{c}\text { Correct } \\
\text { Usage } \\
(n=9)\end{array}$ & $\begin{array}{c}\text { Any } \\
\text { Critical } \\
\text { Error } \\
(n=I I)\end{array}$ & $P$-value \\
\hline Age (years) & $68.6 \pm 7.8$ & $68.9 \pm 8.2$ & 0.805 & $70.1 \pm 6.7$ & $71.0 \pm 8.1$ & 0.474 & $67.8 \pm 6.1$ & $70.4 \pm 9.2$ & 0.479 \\
\hline Male, n (\%) & $86(98.9)$ & 48 (85.7) & 0.002 & 77 (97.5) & $60(90.9)$ & 0.142 & $9(100)$ & $10(90.9)$ & 1.000 \\
\hline $\begin{array}{l}\text { Body mass index } \\
\left(\mathrm{kg} / \mathrm{m}^{2}\right)\end{array}$ & $23.8 \pm 3.4$ & $23.4 \pm 3.5$ & 0.492 & $23.8 \pm 3.7$ & $22.8 \pm 3.3$ & 0.093 & $25.2 \pm 2.8$ & $24.5 \pm 4.8$ & 0.685 \\
\hline Puff burden & $2.3 \pm 1.6$ & $2.6 \pm 1.7$ & 0.286 & $2.4 \pm 1.0$ & $2.5 \pm 1.2$ & 0.533 & $1.4 \pm 0.5$ & $1.7 \pm 0.5$ & 0.220 \\
\hline $\begin{array}{l}\text { COPD duration } \\
\text { (years) }\end{array}$ & $4.4 \pm 4.4$ & $3.1 \pm 3.1$ & 0.066 & $3.1 \pm 4.0$ & $3.7 \pm 4.8$ & 0.413 & $4.1 \pm 4.8$ & $3.7 \pm 4.8$ & 0.857 \\
\hline $\begin{array}{l}\text { Inhaler usage } \\
\text { duration }\end{array}$ & $3.5 \pm 3.4$ & $2.8 \pm 2.6$ & 0.170 & $2.6 \pm 2.9$ & $2.6 \pm 3.4$ & 0.956 & $4.0 \pm 4.8$ & $3.7 \pm 4.8$ & 0.873 \\
\hline $\begin{array}{l}\text { Previous } \\
\text { education on } \\
\text { inhaler }\end{array}$ & $82(94.3 \%)$ & 52 (92.9\%) & 0.737 & 76 (96.2\%) & 61 (92.4\%) & 0.469 & $9(100 \%)$ & 10 (90.9\%) & 1.000 \\
\hline $\begin{array}{l}\text { Previous } \\
\text { education on } \\
\text { COPD }\end{array}$ & $81(93.1)$ & $54(96.4)$ & 0.482 & $75(94.9)$ & $62(93.9)$ & 1.000 & $9(100)$ & $10(90.9)$ & 1.000 \\
\hline $\begin{array}{l}\text { Educational level } \\
\text { Low ( } \leq 6 \text { years) } \\
\text { High ( }>6 \\
\text { years) }\end{array}$ & $\begin{array}{l}31(35.6) \\
56(64.4)\end{array}$ & $\begin{array}{l}22(39.3) \\
34(60.7)\end{array}$ & 0.659 & $\begin{array}{l}22(27.8) \\
57(72.2)\end{array}$ & $\begin{array}{l}31(47.0) \\
35(53.0)\end{array}$ & 0.017 & $\begin{array}{l}3(33.3) \\
6(66.7)\end{array}$ & $\begin{array}{l}6(54.5) \\
5(45.5)\end{array}$ & 0.406 \\
\hline $\begin{array}{l}\text { Percentage } \\
\text { predicted FEV }\end{array}$ & $61.9 \pm 17.4$ & $63.5 \pm 20.2$ & 0.628 & $62.6 \pm 15.7$ & $60.5 \pm 19.3$ & 0.476 & $57.4 \pm 22.1$ & $57.4 \pm 18.3$ & 0.993 \\
\hline $\begin{array}{l}\text { Percentage } \\
\text { predicted DLCO }\end{array}$ & $70.4 \pm 19.0$ & $67.1 \pm 19.7$ & 0.326 & $56.0 \pm 13.0$ & $56.0 \pm 13.0$ & 0.065 & $68.7 \pm 16.0$ & $59.7 \pm 20.5$ & 0.299 \\
\hline $\begin{array}{l}\text { GOLD stage } \\
\text { I, II } \\
\text { III,IV }\end{array}$ & $\begin{array}{l}68(78.2) \\
19(21.8)\end{array}$ & $\begin{array}{l}41(73.2) \\
15(26.8)\end{array}$ & 0.498 & $\begin{array}{l}62(78.5) \\
17(21.5)\end{array}$ & $\begin{array}{l}45(68.2) \\
21(31.8)\end{array}$ & 0.160 & $\begin{array}{l}6(66.7) \\
3(33.3)\end{array}$ & $\begin{array}{l}7(63.6) \\
4(36.4)\end{array}$ & 1.000 \\
\hline mMRC score & $1.2 \pm 0.8$ & $1.5 \pm 0.8$ & 0.042 & $1.2 \pm 0.9$ & $1.4 \pm 0.9$ & 0.130 & $1.2 \pm 0.8$ & $2.1 \pm 1.0$ & 0.058 \\
\hline CAT score & $9.5 \pm 4.9$ & $10.7 \pm 5.8$ & 0.201 & $9.3 \pm 5.2$ & $10.9 \pm 6.3$ & 0.095 & $8.2 \pm 4.6$ & $14.7 \pm 6.7$ & 0.024 \\
\hline MMSE score & $29.5 \pm 1.3$ & $29.1 \pm 2.1$ & 0.180 & $29.7 \pm 0.98$ & $29.2 \pm 1.9$ & 0.130 & $29.6 \pm 1.3$ & $28.2 \pm 3.0$ & 0.224 \\
\hline FSI-I0 score & $45.4 \pm 4.3$ & $42.4 \pm 5.5$ & $<0.001$ & $44.7 \pm 4.3$ & $43.9 \pm 4.6$ & 0.322 & $42.9 \pm 4.0$ & $42.9 \pm 3.8$ & 0.991 \\
\hline PHQ-9 score & $1.5 \pm 3.0$ & $0.9 \pm 1.5$ & 0.137 & $0.9 \pm 1.6$ & $1.1 \pm 2.2$ & 0.715 & $0.8 \pm 1.4$ & $1.4 \pm 2.0$ & 0.462 \\
\hline EQ-5D score & $0.9 \pm 0.1$ & $0.9 \pm 0.1$ & 0.341 & $0.89 \pm 0.07$ & $0.86 \pm 0.10$ & 0.020 & $0.9 \pm 0.1$ & $0.7 \pm 0.3$ & 0.160 \\
\hline $\begin{array}{l}\text { Moderate AEs in } \\
\text { the prior year }\end{array}$ & $37(42.5)$ & $34(60.7)$ & 0.034 & $28(35.4)$ & 27 (40.9) & 0.499 & $4(44.4)$ & $2(18.2)$ & 0.336 \\
\hline
\end{tabular}

(Continued) 
Table 2 (Continued).

\begin{tabular}{|c|c|c|c|c|c|c|c|c|c|}
\hline & \multicolumn{3}{|c|}{ DPI $(n=143)$} & \multicolumn{3}{|c|}{ SMI $(n=145)$} & \multicolumn{3}{|c|}{ pMDI $(n=20)$} \\
\hline & $\begin{array}{c}\text { Correct } \\
\text { Usage } \\
(n=87)\end{array}$ & $\begin{array}{c}\text { Any } \\
\text { Critical } \\
\text { Error } \\
(n=56)\end{array}$ & $P$-value & $\begin{array}{c}\text { Correct } \\
\text { Usage } \\
(n=79)\end{array}$ & $\begin{array}{c}\text { Any } \\
\text { Critical } \\
\text { Error } \\
(n=66)\end{array}$ & $P$-value & $\begin{array}{c}\text { Correct } \\
\text { Usage } \\
(n=9)\end{array}$ & $\begin{array}{c}\text { Any } \\
\text { Critical } \\
\text { Error } \\
(n=I I)\end{array}$ & $P$-value \\
\hline $\begin{array}{l}\text { Severe AEs in the } \\
\text { prior year }\end{array}$ & $13(14.9)$ & $8(14.3)$ & 0.914 & $14(17.7)$ & $19(28.8)$ & 0.113 & I (II.I) & $3(27.3)$ & 0.591 \\
\hline $\begin{array}{l}\text { Frequent AEs in } \\
\text { the prior year }\end{array}$ & $21(24.1)$ & $22(39.3)$ & 0.054 & II (I3.9) & 21 (3I.8) & 0.010 & $3(33.3)$ & I (9.1) & 0.285 \\
\hline
\end{tabular}

Note: Data are presented as the mean \pm standard deviation or number (percentage).

Abbreviations: AE, acute exacerbation; CAT, COPD assessment test; COPD, chronic obstructive pulmonary disease; DLCO, diffusion capacity for carbon monoxide; DPI, dry powder inhaler; EQ-5D, EuroQol-5D; FEV , forced expiratory volume in I second; FSI-10, Feeling of Satisfaction with Inhaler questionnaire; FVC, forced vital capacity; GOLD, Global Initiative for Chronic Obstructive Lung Disease; mMRC, modified Medical Research Council; MMSE, Mini-Mental State Examination; PHQ-9, patient health questionnaire; pMDI, pressurized metered dose inhaler; SMI, soft mist inhaler.

Shorter duration of disease was associated with increased likelihood of poor inhaler technique in patients with COPD and asthma using pMDI and Turbuhaler in previous study. ${ }^{12}$ Failure to hold pMDI or head in a vertical position, and failure to keep Turbuhaler upright were significantly associated with shorter duration of disease. Our study also demonstrated short COPD duration is an independent risk factor for any critical error in DPI users. Structured and detailed education of inhaler technique should be more emphasized on patients with short COPD duration.

Studies on the effect of sex on inhaler error have reported inconsistent results, with most concluding that sex is not a significant factor for inhaler error within the COPD population. ${ }^{7,13,14}$ However, some studies have found an association between female sex and poor inhaler technique. A multinational study enrolling 3681 asthma patients reported that female sex was an independent risk factor for inhaler error (OR 1.51; 95\% CI 1.08-2.10). ${ }^{15}$ Chorao et al found a higher rate of inhaler errors in female asthma and COPD patients (OR 2.68; 95\% CI $1.55-4.65){ }^{16}$ In our study, the number of female patients (17 of 261 patients) was too small to assess whether females are at greater risk of inhaler errors.

An observational multicenter study enrolling 778 patients with moderate to severe asthma showed that high satisfaction with the inhaler was associated with improved disease control, high adherence to inhaler use, and no problems with inhaler use. ${ }^{17}$ Similarly, in our study of COPD patients, low satisfaction with the inhaler was associated with a higher risk of any critical error. Few studies have examined the relationship between satisfaction with the inhaler and inhaler technique. To the best of our knowledge, our study is the first to report a positive association between inhaler satisfaction and inhaler technique. Future multicenter studies are needed to confirm this result in large COPD populations.

Moderate or frequent AEs in the prior year was an independent risk factor for any critical error in our DPI and SMI groups. Previous studies have demonstrated that critical inhaler error is significantly associated with poor disease outcome. Molimard et al found that the proportion of patients with severe AEs in the past 3 months was higher among patients with critical inhaler errors than in those without $(6.9 \%$ vs $3.3 \%, P<0.05) .{ }^{11}$ In adults hospitalized with asthma or COPD, in-hospital instruction in inhaler technique reduced the number of acute care events within 30 days after discharge. ${ }^{18}$ In the multicenter observational study by Melani et al, inhaler misuse by asthma and COPD patients was associated with an increased risk of hospitalization, emergency room visits, requiring oral steroids and antibiotics, and poor disease control as evaluated by an asthma control test. ${ }^{3}$ Taking into account the results of several studies and our own study, inhaler errors can be clearly linked to disease control, including AEs.

An association between a high level of education and fewer inhaler errors has also been reported. In an observational study conducted in India that enrolled 300 asthma or COPD patients, illiterate patients had a $95.2 \%$ error rate, whereas the rate in post-graduates and professionals was $33.3 \%$. ${ }^{19}$ Pothirat et al reported that a low education level was the single most important factor related to incorrect technique in COPD patients in Thailand. ${ }^{7}$ Our study of 
Table 3 Logistic Regression Model for Any Critical Inhaler Error as a Function of Inhaler Type

\begin{tabular}{|c|c|c|c|}
\hline & DPI & SMI & PMDI \\
\hline \multicolumn{4}{|l|}{ Sex } \\
\hline Male & 1 & & \\
\hline Female & $30.35(3.20-288.0)$ & & \\
\hline COPD duration & $0.86(0.75-0.98)$ & & \\
\hline \multicolumn{4}{|l|}{ Educational level } \\
\hline Low ( $\leq 6$ years) & & $2.23(1.10-4.74)$ & \\
\hline High (>6 years) & & 1 & \\
\hline CAT score & & & $\begin{array}{l}1.21 \\
(1.01-1.45)\end{array}$ \\
\hline FSI-10 score & $0.85(0.78-0.93)$ & & \\
\hline \multicolumn{3}{|l|}{ Moderate AEs in the } & \\
\hline Yes & $2.56(1.14-5.72)$ & & \\
\hline No & 1 & & \\
\hline \multicolumn{4}{|l|}{$\begin{array}{l}\text { Frequent AEs in the } \\
\text { prior year }\end{array}$} \\
\hline Yes & & $2.57(1.09-6.07)$ & \\
\hline No & & 1 & \\
\hline
\end{tabular}

Note: Data are presented as odds ratios and $95 \%$ confidence intervals.

Abbreviations: $\mathrm{AE}$, acute exacerbation; CAT, COPD assessment test; COPD, chronic obstructive pulmonary disease; DPI, dry powder inhaler; FSI-10, Feeling of Satisfaction with Inhaler questionnaire; pMDI, pressurized metered dose inhaler; SMI, soft mist inhaler.

COPD patients in South Korea also identified a low education level as an independent risk factor for any critical error, especially among Respimat users.

The CAT score was associated with acceptable inhaler usage in previous studies. Lee et al reported a negative correlation between the CAT score (OR 0.960, 95\% CI $0.927-0.994)$ and the acceptable use of inhalers in elderly patients with respiratory disease. ${ }^{6}$ In other studies, a lower CAT score was associated with high physician- and patient-reported confidence in inhaler usage, ${ }^{20}$ and a shortterm comprehensive education program that included inhaler training and disease management for COPD patients improved the CAT score $(19.6 \pm 12.5$ vs $15.1 \pm 12.3, P<$ $0.05) .^{21}$ Our study provides further evidence of the relationship between disease control as assessed by the CAT and inhaler technique in groups using pMDI-type inhalers.

Previous education on COPD as well as inhaler use is known to be related with better inhaler technique. ${ }^{22,23}$ However, there was no relationship between previous education and inhaler technique in this study. Most of the enrolled COPD patients had been educated on COPD as well as inhaler use (95.4\%). Thus, uneducated number of patients is so small that there is no meaningful difference. It is also important when the patient was educated. If patients were educated a long time before enroll, the effect of education may have already been lost. Therefore, it is difficult to deny the relationship between education and inhaler use as a result of our research.

The limitations of our study are as follows. First, it was a single-center study of COPD outpatients, and only one advanced practice nurse evaluated technique which may cause bias. Inclusion of a small number of women is also a limitation of this study. Second, only a small number of patients used the pMDI type of inhaler, which hindered a generalization of the results of our study. Third, other independent factors known to affect poor inhaler technique, such as comorbidities and duration of inhaler device use, were not evaluated. Fourth, there is no standardized checklist of inhaler yet, and we made our own checklist that can affect the results. However, ours is one of the few studies to have focused on risk factors for inhaler errors in Asian COPD populations. Moreover, it recruited COPD patients using several different modern inhaler devices and obtained meaningful results.

In conclusion, critical inhaler errors were common among patients with COPD, regardless of the type of inhaler device used. Nonetheless, the rates and risk factors for any critical inhaler error differed depending on the device used. Optimal device selection considering the risk factors of inhaler misuse is essential for disease control in COPD patients.

\section{Data Sharing Statement}

The datasets are available from the corresponding author (June Hong Ahn) on reasonable request.

\section{Ethics Statement}

This study was conducted in accordance with all relevant tenets of the Declaration of Helsinki. The protocol was reviewed and approved by the Institutional Review Board of our hospital (no. YUH IRB 2017-09-012-001). Written informed consent was obtained from all patients.

\section{Acknowledgments}

We sincerely thank Mi Suk Lee for assisting with this study and Mi Jeong Nam for her invaluable efforts with respect to data collection.

\section{Author Contributions}

Concept and design: Jang JG, Ahn JH, Lee KH 
Acquisition, analysis, or interpretation of data: Jang JG, Ahn JH, Lee KH

Drafting of the manuscript: Ahn JH

Critical revision of the manuscript: All authors

Statistical Analysis: Jang JG, Ahn JH

Obtained funding: Ahn JH

All authors made substantial contributions to conception and design, acquisition of data, or analysis and interpretation of data; took part in drafting the article or revising it critically for important intellectual content; agreed to submit to the current journal; gave final approval of the version to be published; and agree to be accountable for all aspects of the work.

\section{Funding}

This research was supported by the Bio \& Medical Technology Development Program of the National Research Foundation (NRF) funded by the Ministry of Science \& ICT(grant number 2021M3E5D1A0201526521 and 2021R1C1C100950811).

\section{Disclosure}

There are no competing interests in this work.

\section{References}

1. Park YB, Rhee CK, Yoon HK, et al. Revised (2018) COPD clinical practice guideline of the Korean Academy of Tuberculosis and Respiratory Disease: a summary. Tuberc Respir Dis (Seoul). 2018;81 (4):261-273. doi:10.4046/trd.2018.0029

2. Hwang YI, Park YB, Yoo KH. Recent trends in the prevalence of chronic obstructive pulmonary disease in Korea. Tuberc Respir Dis (Seoul). 2017;80(3):226-229. doi:10.4046/trd.2017.80.3.226

3. Melani AS, Bonavia M, Cilenti V, et al. Inhaler mishandling remains common in real life and is associated with reduced disease control. Respir Med. 2011;105(6):930-938. doi:10.1016/j.rmed.2011.01.005

4. Ahn JH, Chung JH, Shin KC, et al. Critical inhaler handling error is an independent risk factor for frequent exacerbations of chronic obstructive pulmonary disease: interim results of a single center prospective study. Int J Chron Obstruct Pulmon Dis. 2019;14:2767-2775. doi:10.2147/COPD.S234774

5. Singh D, Agusti A, Anzueto A, et al. Global strategy for the diagnosis, management, and prevention of chronic obstructive lung disease: the GOLD science committee report 2019. Eur Respir J. 2019;53 (5):1900164. doi:10.1183/13993003.00164-2019

6. Lee HY, Song JH, Won H-K, et al. Comparing inhaler use technique based on inhaler type in elderly patients with respiratory disease. Tuberc Respir Dis. 2021;84(1):46-54. doi:10.4046/trd.2020.0021

7. Pothirat C, Chaiwong W, Phetsuk N, Pisalthanapuna S, Chetsadaphan N, Choomuang W. Evaluating inhaler use technique in COPD patients. Int J Chron Obstruct Pulmon Dis. 2015;10:12 91-1298. doi:10.2147/COPD.S85681
8. Ahn JH, Chung JH, Shin KC, et al. The effects of repeated inhaler device handling education in COPD patients: a prospective cohort study. Sci Rep. 2020;10(1):19676. doi:10.1038/s41598-020-76961-y

9. Baddar S, Jayakrishnan B, Al-Rawas OA. Asthma control: importance of compliance and inhaler technique assessments. J Asthma. 2014;51(4):429-434. doi:10.3109/02770903.2013.871558

10. Faul F, Erdfelder E, Buchner A, Lang AG. Statistical power analyses using G*Power 3.1: tests for correlation and regression analyses. Behav Res Methods. 2009;41(4):1149-1160. doi:10.3758/BRM.41.4.1149

11. Molimard M, Raherison C, Lignot S, et al. Chronic obstructive pulmonary disease exacerbation and inhaler device handling: real-life assessment of 2935 patients. Eur Respir J. 2017;49 (2):1601794. doi:10.1183/13993003.01794-2016

12. Ocakli B, Ozmen I, Tuncay EA, et al. A comparative analysis of errors in inhaler technique among COPD versus asthma patients. Int J Chron Obstruct Pulmon Dis. 2018;13:2941-2947. doi:10.2147/COPD.S178951

13. Komase Y, Asako A, Kobayashi A, Sharma R. Ease-of-use preference for the ELLIPTA(R) dry powder inhaler over a commonly used single-dose capsule dry powder inhaler by inhalation device-naive Japanese volunteers aged 40 years or older. Int J Chron Obstruct Pulmon Dis. 2014;9:1365-1375. doi:10.2147/COPD.S72762

14. Sriram KB, Percival M. Suboptimal inhaler medication adherence and incorrect technique are common among chronic obstructive pulmonary disease patients. Chron Respir Dis. 2016;13(1):13-22. doi:10.1177/1479972315606313

15. Westerik JA, Carter V, Chrystyn H, et al. Characteristics of patients making serious inhaler errors with a dry powder inhaler and association with asthma-related events in a primary care setting. J Asthma. 2016;53(3):321-329. doi:10.3109/02770903.2015.1099160

16. Chorao P, Pereira AM, Fonseca JA. Inhaler devices in asthma and COPD-an assessment of inhaler technique and patient preferences. Respir Med. 2014;108(7):968-975. doi:10.1016/j.rmed.2014.04.019

17. Plaza V, Giner J, Calle M, et al. Impact of patient satisfaction with his or her inhaler on adherence and asthma control. Allergy Asthma Proc. 2018;39(6):437-444. doi:10.2500/aap.2018.39.4183

18. Press VG, Arora VM, Trela KC, et al. Effectiveness of interventions to teach metered-dose and diskus inhaler techniques. a randomized trial. Ann Am Thorac Soc. 2016;13(6):816-824. doi:10.1513/ AnnalsATS.201509-603OC

19. Arora P, Kumar L, Vohra V, et al. Evaluating the technique of using inhalation device in COPD and Bronchial Asthma patients. Respir Med. 2014;108(7):992-998. doi:10.1016/j.rmed.2014.04.021

20. Amin AN, Ganapathy V, Roughley A, Small M. Confidence in correct inhaler technique and its association with treatment adherence and health status among US patients with chronic obstructive pulmonary disease. Patient Prefer Adherence. 2017;11:1205-1212. doi:10.2147/PPA.S140139

21. Yoo KH, Chung WY, Park JH, et al. Short-term evaluation of a comprehensive education program including inhaler training and disease management on chronic obstructive pulmonary disease. Tuberc Respir Dis (Seoul). 2017;80(4):377-384. doi:10.4046/ $\operatorname{trd} .2017 .0041$

22. Jang JG, Kim JS, Chung JH, et al. Comprehensive effects of organized education for patients with chronic obstructive pulmonary disease. Int J Chron Obstruct Pulmon Dis. 2019;14:2603-2609. doi:10.2147/COPD.S221673

23. Giraud V, Allaert FA, Roche N. Inhaler technique and asthma: feasability and acceptability of training by pharmacists. Respir Med. 2011;105(12):1815-1822. doi:10.1016/j.rmed.2011.07.004 


\section{Publish your work in this journal}

The International Journal of COPD is an international, peer-reviewed journal of therapeutics and pharmacology focusing on concise rapid reporting of clinical studies and reviews in COPD. Special focus is given to the pathophysiological processes underlying the disease, intervention programs, patient focused education, and self management protocols. This journal is indexed on PubMed Central, MedLine and CAS. The manuscript management system is completely online and includes a very quick and fair peer-review system, which is all easy to use. Visit http://www.dovepress.com/testimonials.php to read real quotes from published authors.

Submit your manuscript here: https://www.dovepress.com/international-journal-of-chronic-obstructive-pulmonary-disease-journal 